\title{
FIRE RESISTANCE OF CIRCULAR STEEL TUBES INFILLED WITH ULTRA-HIGH STRENGTH CONCRETE WITH EXTERNAL FIRE PROTECTION
}

\author{
Xiao $\mathrm{Lyu}^{1 *}$ - Erfeng $\mathrm{Du}^{2,3}-\operatorname{Ran} \mathrm{Li}^{2,3}$ \\ ${ }^{1}$ School of Civil Engineering, Shandong Jianzhu University, Jinan 250101, China \\ ${ }^{2}$ School of Civil Engineering, Southeast University, Nanjing 210096, China \\ ${ }^{3}$ Key Laboratory of C \& PC Structures, Ministry of Education, Southeast University, Nanjing 210096, China
}

\begin{tabular}{l}
\hline ARTICLE INFO \\
\hline Article history: \\
Received: 1.1 .2017$. \\
Received in revised form: 24.8 .2017$. \\
Accepted: 25.8 .2017$. \\
\hline Keywords: \\
Finite element analysis \\
Fire protection \\
Fire resistance \\
Circular steel tube \\
Ultra-high strength concrete
\end{tabular}

DOI: http://doi.org/10.30765/er.39.1.8

\section{Introduction}

The use of concrete filled tubular columns is common in high-rise buildings due to their excellent structural performance and the combined effect of steel and concrete working together has many advantages [1]. Their load and fire resistance can be further enhanced by filling them with concrete while the concrete core can restrict inward deformation of the steel tube thus enhancing local buckling resistance [2]. What's more, there's no need for additional formwork because of the steel tube [3]. The concrete core acts as heat sink which reduces the

\begin{abstract}
:
In this paper, a non-linear three-dimensional finite element model is presented in order to study the behaviour of axially loaded ultra-high strength concrete filled circular hollow tubular columns exposed to fire. Ultra-high strength concrete with compressive strength greater than $180 \mathrm{~N} / \mathrm{mm}^{2}$ has been developed for concrete filled tubes for use in high-rise buildings. This paper studies the structural performance of fire protected ultra-high strength concrete filled tubular columns exposed to the standard ISO fire. The aim of this work is to understand and represent the behaviour of axially loaded ultra-high strength concrete filled circular hollow tubular columns in fire situations and to compare calculation results with experiment. The numerical analyses are carried out using a general finite element analysis package ABAQUS and the results are validated against the test results in terms of heat distribution and mechanical behavior. Comparison with the test results showed a reasonable agreement with finite element results in terms of temperature prediction and load displacement behavior during the fire.
\end{abstract}

temperature of the steel tube when the concrete filled tube is subjected to fire [4]. The reasonable periods of fire resistance can be achieved without the need for external protection if the concrete inside the steel tube is reinforced [5]. This would eliminate external fire protection and reduce the cost of inspection and maintenance of the fire protection material.

Although the fire performance of hollow steel section columns filled with normal strength concrete (NSC) is well established [6], the fire design rules cannot be extended to ultra-high strength concrete (UHSC) filled steel columns. This is mainly attributed to faster deterioration of material 
properties of the UHSC as compared to that of the NSC.

Studies on the fire resistance of steel tubular columns infilled with normal and high strength concrete have been carried out by many researchers [7][8][9]. Recent research focuses on the use of UHSC as infilling material to form concrete filled tubular members (CFTs) [ 10$][11][12]$. Steel tubular members infilled with the UHSC with compressive strength up to $180 \mathrm{~N} / \mathrm{mm}^{2}$ provide higher compression resistance and, therefore, smaller column size. Liew [13] have investigated the behavior of such columns in both ambient temperature and fire situations.

The UHSC material is very brittle and has no post peak behavior after it is loaded beyond the maximum load. This is a serious drawback and it limits its application in construction [14]. But when the UHSC is used in concrete filled tubes, the confinement provided by the steel tube can improve the post-peak ductility of the ultra-high strength concrete depending on the steel contribution ratio as observed by Liew [15] in the experimental studies. This paper presents the nonlinear finite element analysis model to simulate the fire performance of the ultra-high strength concrete filled tubular (UHSCFT) columns exposed to the standard fire condition. The composite action between the steel and concrete has been considered in the numerical model. The column is subjected to axial compression followed by heating under standard ISO fire until failure. The analysis considers the influences of temperature on the strength and modulus of the UHSC material based on the test data from Xiong [16]. The accuracy of the numerical model is established by comparing the numerical results with test results.

\section{Temperature calculation of concrete filled tubular members}

The specimens for the analysis are taken from Xiong [16]. All the columns are $3810 \mathrm{~mm}$ long from end plate to end plate with $3000 \mathrm{~mm}$ long exposed to fire in the furnace, and the details are shown in the Table 1. The prediction of the temperature field of UHSCFT column is based on the fire temperature in the furnace.

Table 1. Details of the UHSCFT columns

\begin{tabular}{|c|c|c|c|c|c|c|c|}
\hline Specimen & $\begin{array}{c}\text { Diameter } \times \\
\text { thickness } \\
D(\mathrm{~mm}) \times t_{\mathrm{s}}(\mathrm{mm})\end{array}$ & $\begin{array}{l}\text { Steel yield } \\
\text { strength } \\
f_{\mathrm{y}}(\mathrm{MPa})\end{array}$ & $\begin{array}{l}\text { Modulus of } \\
\text { Elasticity } \\
E_{\mathrm{s}}(\mathrm{GPa})\end{array}$ & $\begin{array}{c}\text { Concrete } \\
\text { Cylinder Strength } \\
f_{\mathrm{c}}(\mathrm{MPa})\end{array}$ & $\begin{array}{c}t_{\mathrm{p}}^{*} \\
(\mathrm{~mm})\end{array}$ & $\delta^{*}$ & $\bar{\lambda}^{*}$ \\
\hline UCZ-1 & $219.1 \times 16$ & \multirow{3}{*}{432} & \multirow{3}{*}{204} & 161 & 5.9 & 0.50 & 1.01 \\
\hline UCZ-2 & $219.1 \times 16$ & & & 168 & 6.4 & 0.49 & 1.02 \\
\hline UCZ-3 & $219.1 \times 16$ & & & 164 & 8.1 & 0.49 & 1.02 \\
\hline UCZ-4 & $273 \times 16$ & 422 & 203 & 181 & 6.8 & 0.40 & 0.86 \\
\hline UCZ-5 & $273 \times 10$ & 418 & 201 & 180 & 8.6 & 0.28 & 0.94 \\
\hline
\end{tabular}

Notes: $t_{\mathrm{p}}$ is thickness of fire protection. $\delta=A_{\mathrm{a}} f_{\mathrm{y}} /\left(A_{\mathrm{a}} f_{\mathrm{y}}+A_{\mathrm{c}} f_{\mathrm{c}}\right)$ is the steel contribution ratio. $\bar{\lambda}$ is the relative slenderness.

The fire resistance of ultra-high strength concrete filled tubular (UHSCFT) columns depends on the fire temperature to which the column is exposed, the temperature field in the column, the strength of the materials at elevated temperature and the member deformations during the fire exposure. Using the temperature-dependent thermal properties of the concrete and steel, the temperature history of the column can be obtained by solving the heat balance equation [17]. A two-dimensional nonlinear thermal analysis model for the UHSCFT column exposed to a fire on four sides is considered, with the assumption that no heat is flowing along the longitudinal axis [18][19]. The finite element simulations for both the heat transfer and structural analyses are conducted using the general finite element analysis package ABAQUS.

One of the main ingredients in making the UHSC is bauxite aggregate which has better fire resistance than the siliceous aggregate as use in normal strength concrete (NSC). The residual strength and the strength reduction factor of USHC are larger than those of NSC at elevated temperature. Furthermore, comparing the UHSC with the NSC, the strength reduction factor of UHSC is similar to NSC with calcareous aggregate, but higher than NSC with siliceous aggregate at temperature higher than $200^{\circ} \mathrm{C}$. In other words, the strength and elastic modulus of 
UHSC are reduced less than those of NSC at elevated temperature. However, explosive spalling behavior of UHSC was observed when it was heated up to $500{ }^{\circ} \mathrm{C}$. But this can be prevented by adding polypropylene fibers $0.1 \%$ volume of concrete [20]. Using the temperature-dependent thermal properties of the concrete and steel, the temperature history of the column can be obtained by solving the heat balance equation. A two-dimensional nonlinear thermal analysis model for the USCFT column exposed to a fire on four sides is considered, with the assumption that no heat is flowing along the longitudinal axis. In the paper, the circular hollow steel column heat transfer equation and the heat flux equation, including convection and radiation, is adopted respectively as below [21],

$$
\begin{gathered}
\rho c \frac{\partial T}{\partial t}=k\left(\frac{\partial^{2} T}{\partial r^{2}}+\frac{1}{r} \frac{\partial T}{\partial r}+\frac{\partial^{2} T}{\partial z^{2}}\right) \\
k \frac{\partial T}{\partial n}=\alpha_{\mathrm{c}}\left(T_{\mathrm{f}}-T\right)+\varepsilon \sigma\left[\left(T_{\mathrm{f}}+273\right)^{4}-(T+273)^{4}\right]
\end{gathered}
$$

where $c$ is the specific heat $(\mathrm{J} / \mathrm{kg} \cdot \mathrm{K}), \rho$ is the density of the material $\left(\mathrm{kg} / \mathrm{m}^{3}\right), k$ is the heat transfer coefficient $(\mathrm{W} / \mathrm{m} \cdot \mathrm{K}), t$ is the fire duration time $(\mathrm{s}), T_{\mathrm{f}}$ is the temperature of the fire $\left({ }^{\circ} \mathrm{C}\right), T$ is the temperature of the column surface $\left({ }^{\circ} \mathrm{C}\right), \alpha_{\mathrm{c}}=25$ $\mathrm{W} / \mathrm{m}^{2} \cdot \mathrm{K}$ is the convection coefficient, $\varepsilon=0.5$ is the resultant emissivity of the furnace and the exposed refractory surface, $\sigma=5.67 \times 10^{-8} \mathrm{~W} /\left(\mathrm{m}^{2} \cdot \mathrm{K}^{4}\right)$ is the Stefan-Boltzmann constant. Heat flux continuity is assumed at the interface between the fire protection material and steel, as well the same assumption between the steel and concrete.

\subsection{Thermal properties of the ultra-high strength concrete (UHSC)}

The thermal properties include the thermal conductivity, specific heat, thermal expansion, and the mass loss of the material at elevated temperatures.
There are three material models of thermal properties which are often adopted for the heat transfer calculations. One is the Lie's thermal model, the second one is in the AIJ code model, and the third one is the Eurocode model. In this paper, the thermal model is based on the Eurocode model which considers the effects of water in the concrete on density and specific heat. Generally, the lower limit of thermal conductivity is used for normal strength concrete (NSC), while the upper limit is considered for high strength concrete (HSC) and ultra-high strength concrete (UHSC). The moisture content is assumed to be $3 \%$ for NSC and HSC, whereas it is ignored for UHSC.

\subsection{Thermal properties of the fire protection material}

In the fire tests reported in Xiong [16], the fire protection material was a mixture of Portland cement (40\%), perlite (25\%), vermiculite (20\%) and water (15\%) by weight. The thermal properties are assumed not to change with temperature. The thermal conductivity $=0.116 \mathrm{~W} / \mathrm{m} \cdot \mathrm{K}$, specific heat $=1010 \mathrm{~J} / \mathrm{kg} \cdot \mathrm{K}$ and density $=305 \mathrm{~kg} / \mathrm{m}^{3}$ are adopted based on the test data.

\subsection{Thermal analysis of the specimens}

The initial ambient temperature is set as $20^{\circ} \mathrm{C}$. In the thermal analysis, 4-node shell element (DS4) is adopted to model the steel tube and 8-node brick element (DC3D8) for the concrete core and the fire protection with three layers along its thickness. The heat convection and radiation are considered as boundary conditions in the thermal analysis as shown in Figs. 1a-c. The height of specimen exposed to fire is $3.0 \mathrm{~m}$, while the height of specimen is 3.81 $\mathrm{m}$. The composite column is subjected to uniform heating (close to an ISO standard fire) from the surrounding air in the furnace during the entire heating process. 


\section{(DC3D8)}

Element of fire protection

(DS4)

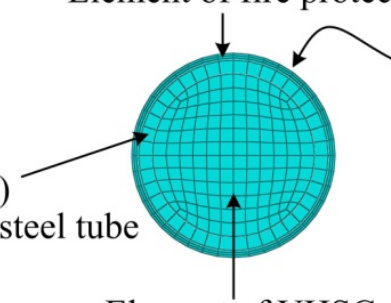

Element of UHSC

(DC3D8)
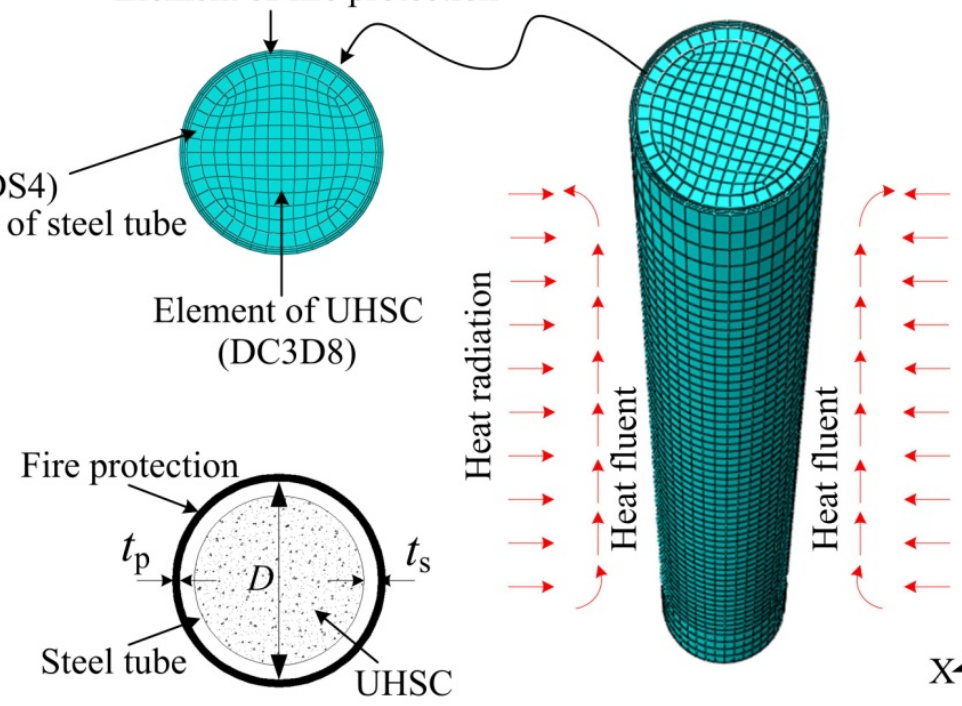

(a) Cross section

(b) Thermal analysis model

(c) Results of thermal analysis

Figure 1. Boundary condition for temperature field and calculation results.

\subsection{Comparison between the predicted and experimental results}

There are three measure points in the UHSCFT column. Point 1 is at the centre of column crosssection, point 2 is at the position of $r / 2$ ( $r$ is radius of concrete core) and Point 3 is at the edge of the concrete core. The predicted temperatures are compared based on the finite element analyses to the measured temperatures from the tests, as shown in Fig. 2. The furnace temperature was measured and plotted in Figs. 2a-e.

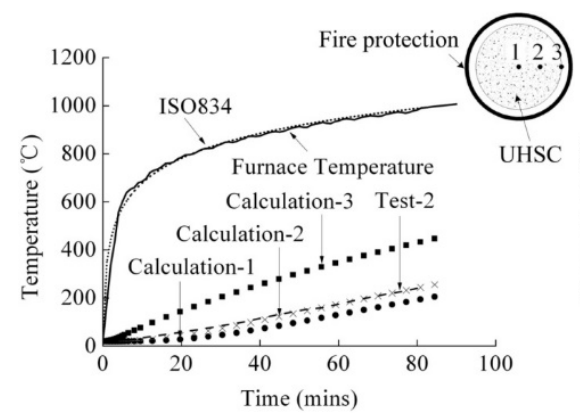

(a) Specimen UCZ-1

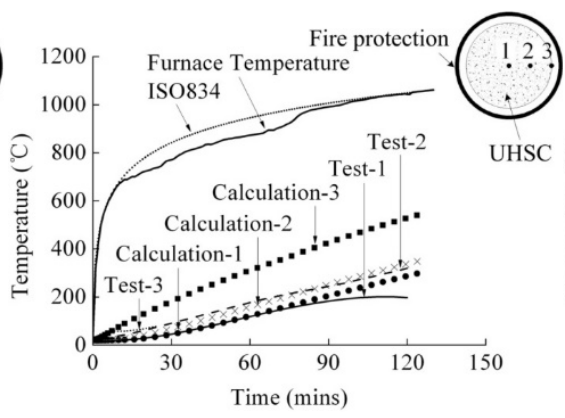

(b) Specimen UCZ-2

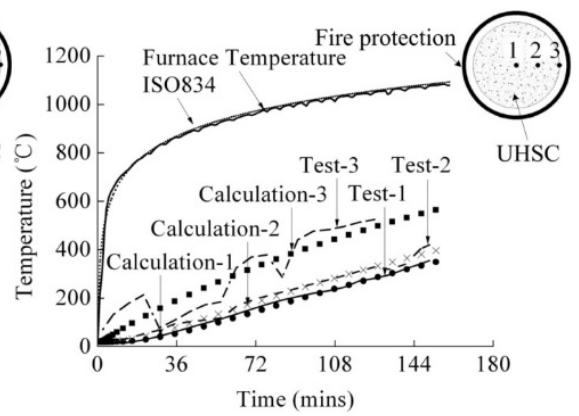

(c) Specimen UCZ-3

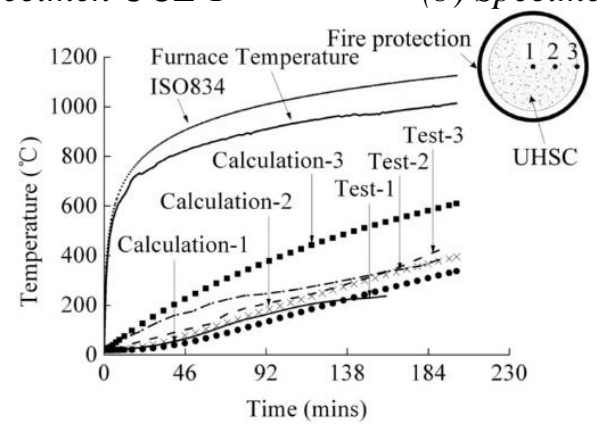

(d) Specimen UCZ-4

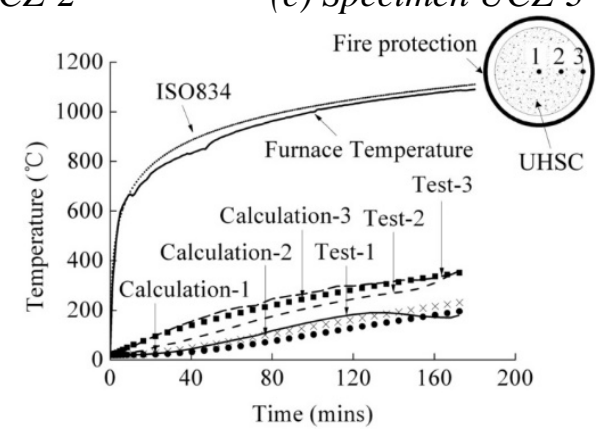

(e) Specimen UCZ-5

Figure 2. Comparison between the predicted and measured temperatures for specimens UCZ-1 5. 
For specimen UCZ-1, the measured temperature at point 2 compared well with the predicted results. The mean error between the predicted temperature and measured temperature is less than $5 \%$, what's more, with the temperature increasing, the value of the error becomes decreasing. The other two thermocouples at points 1 and 3 did not record any readings as they were damaged during the preparation of the test specimen. For specimen UCZ2 , the mean errors between the predicted temperature and measured temperature for points 1,2 and 3 are less than $5 \%$, although the error is a little big for point 1 after exposing to fire 90 minutes. For specimens UCZ-3 and UCZ-5, the comparisons showed that the predicted temperatures were in reasonable agreement with the measured values. As shown in Fig. 2c, the mean errors between the predicted temperature and measured temperature for points 1 and 2 are less than $4 \%$, although the mean error is about $12 \%$ for point 3 . For specimen UCZ-5, the mean errors between the predicted temperature and measured temperature for points 1 and 3 are less than $6 \%$, although the mean error is about $15 \%$ for point 2 . The same reason was applied to the measure point 3 of UCZ-4, while the predicted temperature at points 1 and 2 are acceptable compared with the measured values.

\section{Mechanical properties at elevated temperature}

\subsection{Ultra-high strength concrete (UHSC)}

There is limited information on the mechanical properties of the UHSC at elevated temperature. Xiong [16] conducted tests to evaluate the elastic modulus and compressive strength of the UHSC at elevated temperatures. In the tests, cylinder specimens with diameter $=100 \mathrm{~mm}$ and height $=200$ $\mathrm{mm}$ were prepared. The specimens were heated in a furnace without pre-loading at a rate of $5^{\circ} \mathrm{C} / \mathrm{min}$ until the target temperature was reached. Dosage of $0.1 \%$ polypropylene in volume was added into the UHSC in case of spalling during heating. The target temperatures ranged between $100^{\circ} \mathrm{C}$ to $800^{\circ} \mathrm{C}$ at an increment of $100^{\circ} \mathrm{C}$. Once the target temperature was reached, it was held for 4 hours to ensure that the temperature was uniformly distributed inside the test specimen. Finally, the specimen was subjected to compression until failure with displacement rate $0.4 \mathrm{~mm} / \mathrm{min}$ during loading. Spalling was not observed during heating of all specimens. A typical stress-strain relationship of the UHSC elevated for specimen UCZ-1 is shown in Fig. 3. The test data were fitted into the stress-strain models in Eurocode 2 [22] as follows:

$$
\sigma=\frac{3 \varepsilon f_{\mathrm{c}, \theta}}{\varepsilon_{\mathrm{c} 1, \theta}\left[2+\left(\frac{\varepsilon}{\varepsilon_{\mathrm{c} 1, \theta}}\right)^{3}\right]} \quad 0 \leq \varepsilon \leq \varepsilon_{\mathrm{cu} 1, \theta}
$$

Where, $f_{\mathrm{c}, \theta}$ is the compressive strength, $\varepsilon_{\mathrm{c} 1, \theta}$ is the strain corresponding to $f_{\mathrm{c}, \theta}, \varepsilon_{\mathrm{cu} 1, \theta}$ is the strain for defining range of the descending branch.

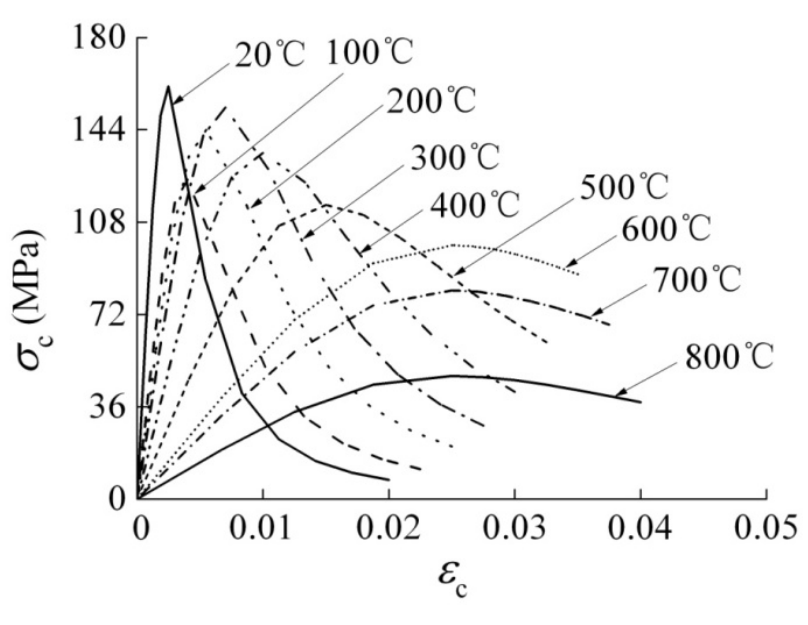

Figure 3. Stress-strain relationship for the UHSC of UCZ-1 at various temperatures.

Seen from Fig. 3, the peak stress decreases sharply at $100^{\circ} \mathrm{C}$ and recovery was observed at the temperature range between $100^{\circ} \mathrm{C} \sim 300^{\circ} \mathrm{C}$, which is the same as the compressive strength. The stress decreases sharply after the peak stress at temperature range between $20^{\circ} \mathrm{C} \sim 300^{\circ} \mathrm{C}$, but it decreases gently at temperature range between $400^{\circ} \mathrm{C} \sim 800^{\circ} \mathrm{C}$.

\subsection{Steel tube}

Eurocode 3 [23] provides the equations to describe the elastic modulus and effective strength of steel at elevated temperature. In the transient-state tests, the preload levels are applied as percentages of the effective yielding strength at $2 \%$ strain at ambient temperature and the specimen was heated under a constant preload until it fails. The preload were applied under load control. Load control mode was 
adopted since it could maintain the preloads during the following heating. The strain-temperature relations were recorded at temperature increment of $100{ }^{\circ} \mathrm{C}$. As a result, a temperature-strain curve is recorded during the testing, which can be converted into stress-strain curve. The reduction factors of elastic modulus, yield strength and the relationship of stress and strain at elevated temperature given in Eurocode 3:1-2 are adopted for the numerical analysis. A typical stress-strain relationship of steel tube at elevated for specimen UCZ-1 is shown in Fig. 4.

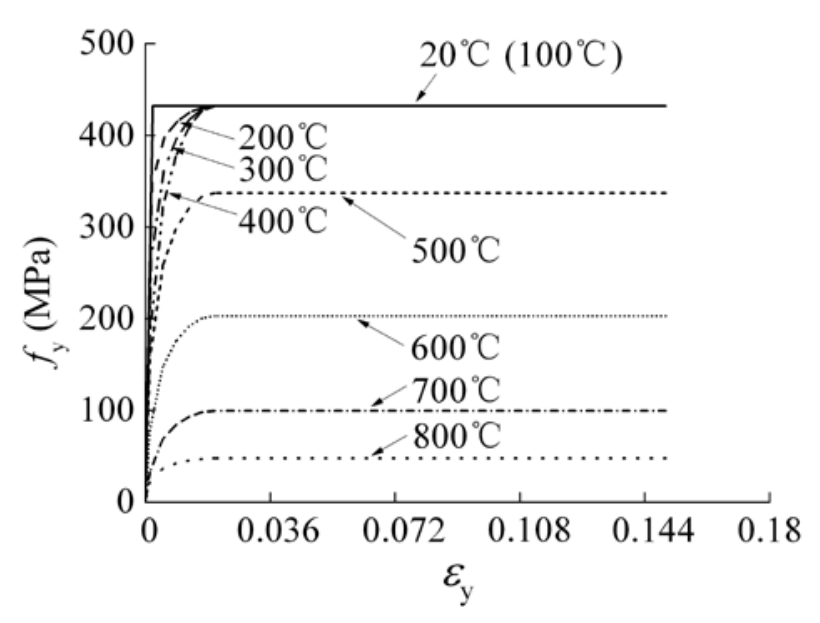

Figure 4. Stress-strain relationship for steel of UCZ-1 at various temperatures.

\section{Fire Resistance of the UHSCFT Columns}

\subsection{Eurocode 4 approach}

According to the simplified method in Eurocode 4 [24], the plastic resistance of the concrete filled circular cross-section may be calculated as:

$$
N_{\mathrm{pl}, \mathrm{Rk}}=A_{\mathrm{a}} f_{\mathrm{y}}+A_{\mathrm{c}} f_{\mathrm{ck}}
$$

if $\bar{\lambda}>0.5$. Otherwise, concrete confinement effect may be considered in calculating the cross-section plastic resistance as:

$$
N_{\mathrm{pl}, \mathrm{Rk}}=A_{\mathrm{a}} \eta_{\mathrm{a}} f_{\mathrm{y}}+A_{\mathrm{c}} f_{\mathrm{ck}}\left(1+\eta_{\mathrm{c}} \frac{t}{d} \frac{f_{\mathrm{y}}}{f_{\mathrm{ck}}}\right)
$$

Where $A_{\mathrm{a}}$ and $A_{\mathrm{c}}$ are cross-sectional areas of the steel section, concrete core respectively. $\eta_{\mathrm{a}}$ and $\eta_{\mathrm{c}}$ are the steel strength reduction and the concrete strength enhancement factor, respectively. $f_{\mathrm{y}}$ and $f_{\mathrm{ck}}$ are characteristic strengths of structural steel and concrete core respectively. $t$ is the wall thickness of steel tube, $d$ is the overall diameter of composite column.

To account for overall buckling of the column, the reduction factor $\chi$ is given in terms of the relative slenderness $\bar{\lambda}$ and the corresponding buckling curve as follows,

$$
\chi=\left(\Phi+\sqrt{\Phi^{2}-\bar{\lambda}^{2}}\right)^{-1} \leq 1.0
$$

where, $\left.\Phi=0.5\left[1+\alpha(\bar{\lambda}-0.2)+\bar{\lambda}^{2}\right)\right]$ and

$$
\bar{\lambda}=\sqrt{\frac{N_{\mathrm{pl}, \mathrm{Rk}}}{N_{\mathrm{cr}}}}
$$

$\alpha$ is an imperfection factor corresponding to the appropriate buckling curve. For concrete filled tubes, buckling curve "a" and $\alpha=0.21$ are adopted if the reinforcement ratio does not exceed $3 \%$. In the tests, there is no reinforcement in the UHSCFT columns, therefore $\alpha=0.21$ is adopted herein. For comparison with test results, $N_{\mathrm{pl}, \mathrm{Rk}}$ calculated from Eq. (4) or (5) should be based on characteristic strengths. $N_{\text {cr }}=\pi^{2}(E I)_{\text {eff }} / l_{\mathrm{e}}^{2}$ is the Euler buckling load of the composite column, and $(E I)_{\mathrm{eff}}=E_{\mathrm{a}} I_{\mathrm{a}}+0.6 E_{\mathrm{cm}} I_{\mathrm{c}}$ is the effective flexural stiffness of the composite cross-section, where $E_{\mathrm{a}}$ is the modulus of elasticity of the structural steel and $E_{\mathrm{cm}}$ is the secant modulus of elasticity of concrete. $I_{\mathrm{a}}$ and $I_{\mathrm{c}}$ are the second moments of area of the structural steel section and the uncracked concrete section respectively.

The characteristic buckling resistance of composite column subject to compression is given as

$$
N_{\mathrm{b}, \mathrm{Rk}}=\chi N_{\mathrm{pl}, \mathrm{Rk}}
$$

\subsection{The thermal-mechanical analysis}

During the thermal stress analysis, the element mesh remains the same as the temperature field analysis without fire protection. But the element type is changed from heat transfer element to thermal mechanical element [25].

In the thermal-mechanical analysis, 8-node brick element (C3D8R) is adopted for the UHSC core and 4-node shell element (S4R) for steel tube. The finite element meshes for the column cross-section is 
shown in Fig. 5a. The column is simply supported at both ends with the boundary conditions as shown in Fig. 5a.

The observed failure mode of specimen UCZ-3 and the predicted failure mode from finite element model (FEM) are shown in Figs. 5c-d. The temperatures, stresses and strains at the centre of each element are assumed to be representative of those of the entire element. Furthermore, it is assumed that the steel and the concrete had the same temperature, $\mathrm{t}$, at the interface [1]. Mesh convergence studies have been performed to study the sensitivity of the mesh size on the predicted results. An optimized mesh size of 20mm (length):20mm (width):60mm (depth) for the part of specimen inside furnace, $20 \mathrm{~mm}$ (length):20mm (width):100mm (depth) for the rest part of specimen outside furnace was selected to ensure that the predicted results are within $2 \%$ error.
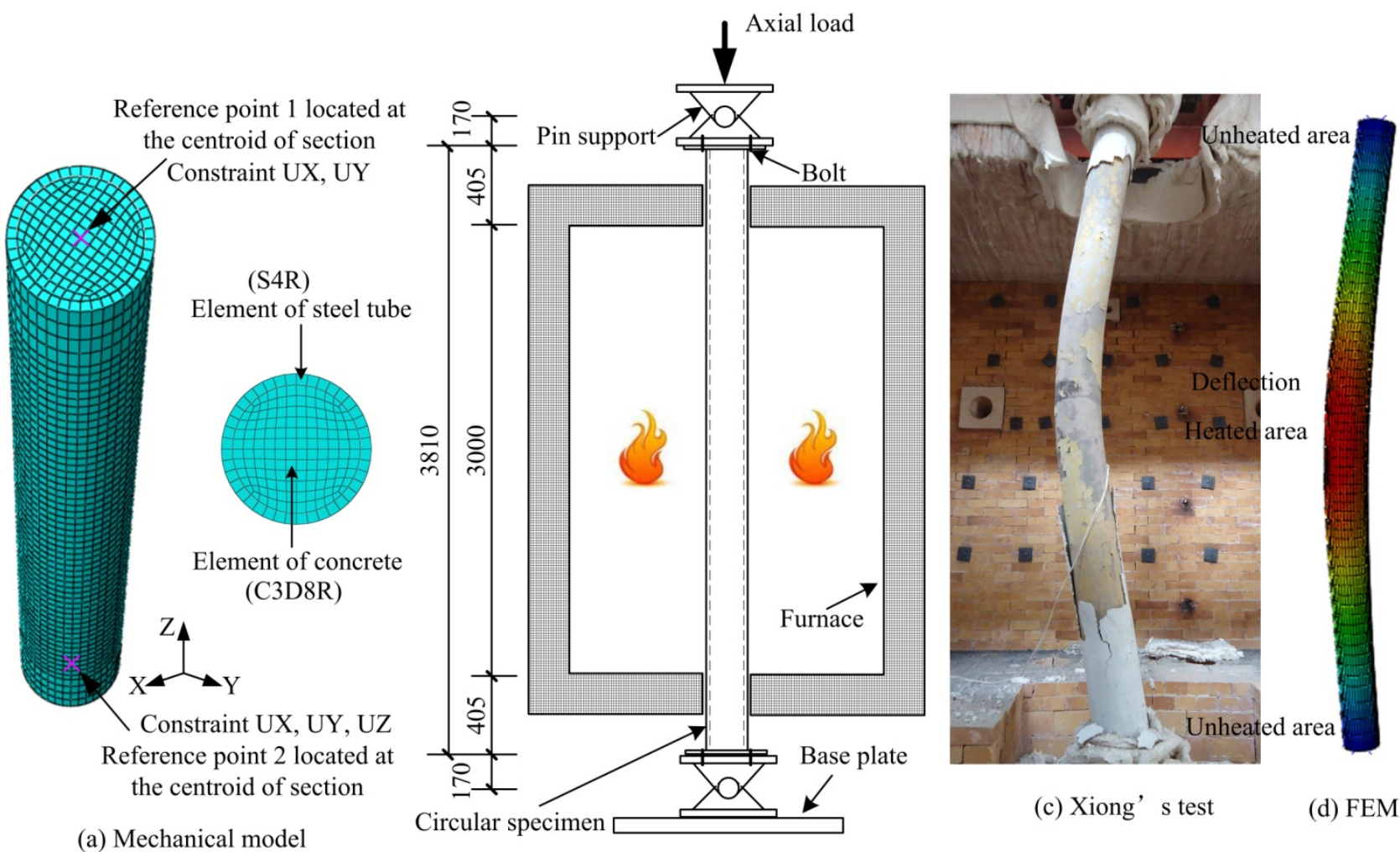

(c) Xiong' s test

(d) FEM

(b) Schematic diagram

Figure 5. Boundary conditions for mechanical models and comparison of experimental and numerical deformed shapes after fire exposure for specimen UCZ-3.

The time-dependent thermal-mechanical analysis was performed using the ABAQUS, a general nonlinear finite element program. The column is assumed to have an initial bow imperfection approximating a half-sine curve of mid-height magnitude of Length//1000 [ 26 ]. This member imperfection has been adopted based on the first buckling mode shape of pin-ended column subject to axial compression.

The value of friction coefficient $\mu=0.2$ to 0.5 is assumed between the steel tube and concrete core. As for the friction coefficient in the tangential direction, this factor has little effect on the fire response of composite columns according to the previous research done in Ellobody [27] and thus $\mu=$ 0.25 is assumed. A "Hard" contact formulation is used in the transverse direction normal to the concrete core surface to capture the contact pressure between the steel and concrete surfaces when they are in contact and allow for separation when the two surfaces move in indifferent directions. Sensitivity study on the friction coefficient has been carried out based on specimen UCZ-3. The result is shown in Fig. 6. According to the analysis results, the influence of friction coefficient on the fire resistance of composite column is insignificant when the value is between 0.3 and 0.5 . The use of $\mu=0.2$ causes convergence problem near the failure temperature. 
The use $\mu=0.3$ is most appropriate as the predicted displacement-time curve is closer to the test result. Finally, $\mu=0.3$ is selected for the friction coefficient in longitudinal direction.

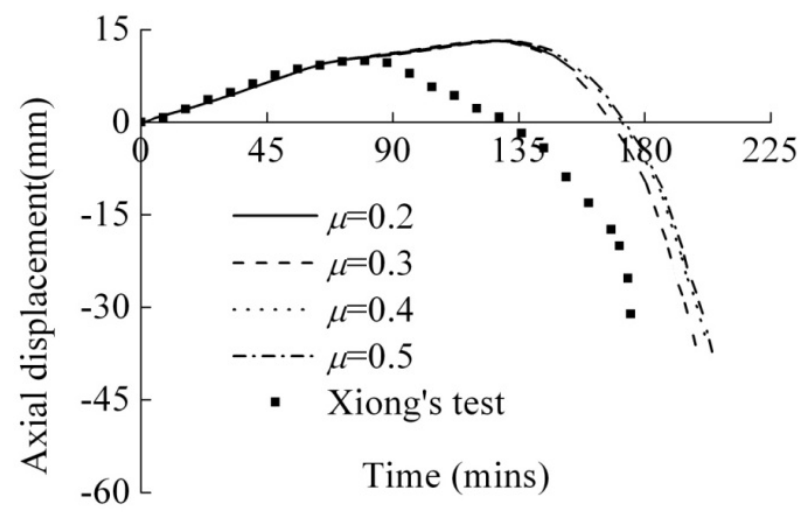

Figure 6. Comparison of test and predicted results with different friction coefficients
The period of time that a column can maintain the compressive load when subjected to an ISO-834 Standard fire is determined. For a column member subject to compression, failure occurs when either of the following two criteria is reached:

(1) The axial deformation of the column reaches $0.01 \mathrm{~L} \mathrm{~mm}$, or

(2) The axial deformation velocity exceeds $0.003 \mathrm{~L}$ $\mathrm{mm} / \mathrm{min}$, where $\mathrm{L}$ is the fire exposed length of column in millimeter.

The results from the numerical analyses and tests are shown in Figs. 7a-e, and the comparisons are given in Table 2. The error of predicting the fire resistance of the concrete filled tubular columns, as compared to the test results is within $15 \%$. The error is considered to be reasonable and the numerical model will be used for parametric analyses in the subsequent sections.

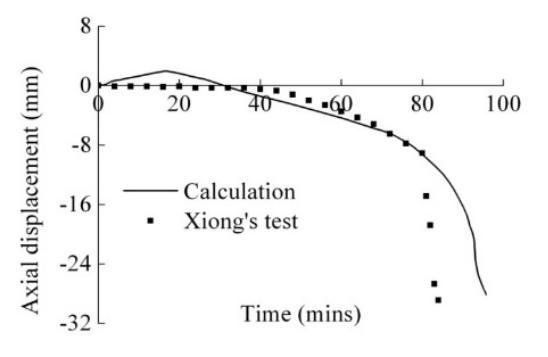

(a) Specimen UCZ-1

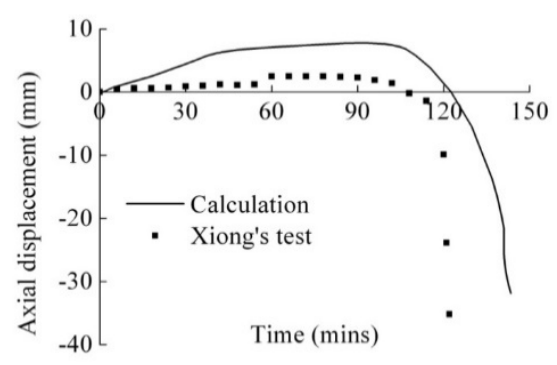

(b) Specimen UCZ-2

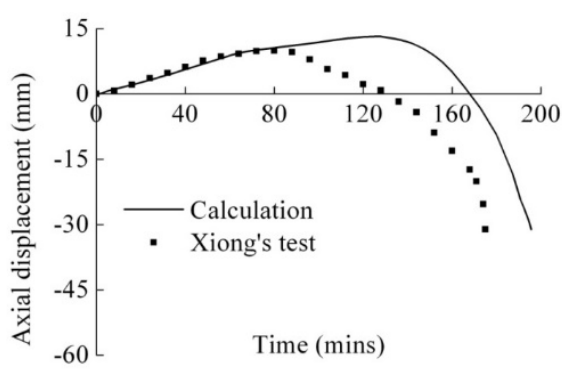

(c) Specimen UCZ-3

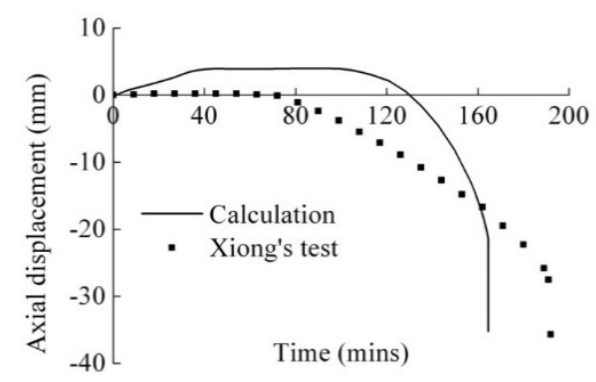

(d) Specimen UCZ-4

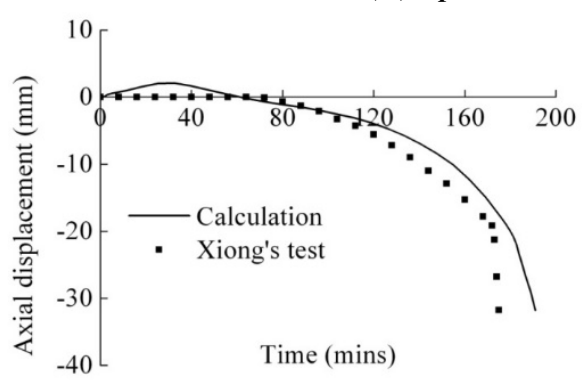

(e) Specimen UCZ-5

Figure 7. Comparison of fire resistance between the calculation results and experimental results.

Table 2. Comparison of fire resistance time between the predicted and test results

\begin{tabular}{|c|c|c|c|c|c|}
\hline Specimen & $t_{\mathrm{p}}(\mathrm{mm})$ & $\beta^{*}$ & FR $^{*}$-Predicted (min) & FR $^{*}$-Experiment (min) & Error (\%) \\
\hline UCZ-1 & 5.9 & 0.63 & 97 & 84 & 13 \\
\hline UCZ-2 & 6.4 & 0.59 & 140 & 122 & 15 \\
\hline UCZ-3 & 8.1 & 0.47 & 195 & 175 & 11 \\
\hline UCZ-4 & 6.8 & 0.53 & 165 & 191 & -14 \\
\hline UCZ-5 & 8.6 & 0.56 & 191 & 175 & 9 \\
\hline
\end{tabular}

Note: "FR" is the fire resistance time. " $\beta$ " is load ratio. 


\section{Conclusion}

In this paper, a finite element model (FEM) is proposed. Numerical heat transfer and nonlinear thermal-mechanical analyses are carried out to investigate the load displacement behavior and fire resistance of steel tubular members infilled with ultra-high strength concrete. Based on the study, several conclusions can be drawn below:

(1) The FEM is used to analyze the structural behavior of the UHSCFT columns to gain insight into the failure mechanism. Considered the interaction between concrete and steel tube, generally, the temperatures, the fire resistance, and the axial deformation of the UHSCFT columns calculated based on the Eurocode material model are in reasonable agreement with the experimental results. The FEM proposed could be used to predict the fire behaviour of the UHSCFT columns in the buildings.

(2) Sensitivity study about the friction coefficient has been carried out based on specimen UCZ-3. According to the analysis results, the influence of friction coefficient $\mu=0.3$ is most appropriate as the predicted displacement-time curve is closer to the test result. So $\mu=0.3$ is selected for the friction coefficient in specimen longitudinal direction.

(3) The temperature distribution in the cross section, fire resistance and axial-load deformation of the UHSCFT columns have been predicted using the finite element model and compared well with the experimental results. Based on that, the numerical models can be used to study the important parameters that will affect the fire resistance of UHSC filled tubular columns in the future.

\section{Acknowledgements}

The research work has been supported by the National Key Technology R\&D Program of China during the 12th Five-Year Plan Period (No. 2012BAJ13B01). The financial support is highly appreciated. The authors are grateful to Professor J. Y. Richard Liew, Department of Civil and Environmental Engineering, National University of Singapore, for his useful comments.

\section{References}

[1] Song, T.Y., Han, L.H., Uy, B.: Performance of CFST column to steel beam joints subjected to simulated fire including the cooling phase, J.
Constr. Steel Res., 66 (2010), 591-604.

[2] Shu, G.P., Lv, X.: Ultimate bearing capacity factor and whole process analysis for large size concrete filled steel tube columns, The IES Journal Part A: Civil and Structural Engineering, 6 (2013) 2, 165-172.

[3] Qu, X.S., Chen, Z.H., Sun, G.J.: Axial behaviour of rectangular concrete-filled coldformed steel tubular columns with different loading methods, Steel Compos. Struct., 18 (2015) 1, 71-90.

[4] Xiao, J.Z., Li, Z.W., Xie, Q.H., Shen, L.M.: Effect of strain rate on compressive behaviour of high-strength concrete after exposure to elevated temperatures, Fire Safety Journal, 83 (2016), 25-37.

[5] Moliner, V., Espinos, A., Romero, M.L., Hospitaler, A.: Fire Behavior of Eccentrically Loaded Slender High Strength Concrete-Filled Tubular Columns, J. Constr. Steel Res., 83 (2013), 137-146.

[6] Kodur, V.K.R., Lie, T.T.: Fire performance of concrete-filled hollow steel columns, Journal of Fire Protection Engineering, 7 (1995), 3, 89-98.

[7] Wang, K., Young, B.: Fire resistance of concrete-filled high strength steel tubular columns, Thin-Walled Struct., 71 (2013), 46-56.

[8] Choi, E.G., Kim, H.S., Shin, Y.S.: Performance of fire damaged steel reinforced high strength concrete (SRHSC) columns, Steel Compos. Struct., 13 (2012), 6, 521-537.

[9] Yang, H., Liu, F.Q., Gardner, L.: Post-fire behaviour of slender reinforced concrete columns confined by circular steel tubes, ThinWalled Struct., 87 (2015), 12-29.

[10] Yang, Z., Zhang, Y., Chen, M., Chen, G.: Numerical simulation of ultra-strength concrete-filled steel columns, Engineering Review, 33 (2013), 3, 211-217.

[11] Choe, G., Kim, G., Gucunski, N., Lee, S.: Evaluation of the mechanical properties of 200 MPa ultra-high-strength concrete at elevated temperatures and residual strength of column, Const. Build. Mater., 86 (2015), 159-168.

[12] Shin, H.O., Yoon, Y.S.;Cook, W.D., Mitchell, D.: Effect of confinement on the axial load response of ultrahigh-strength concrete columns, J. Struct. Eng., 141 (2015), 6, 04014151.

[13] Liew, J.Y.R., Xiong, M.X., Xiong, D.X.: Design of high strength concrete filled tubular columns for tall buildings. Int. J. High-Rise Build., 3 (2014), 3, 1-7. 
[14] Xiong, M.X., Liew, J.Y.R.: Mechanical bahviour of ultra-high strength concrete at elevated temperatures and fire resistance of ultra-high strength concrete filled steel tubes, Materials \& Design, 104 (2016), 414-427.

[15] Liew, J.Y.R., Xiong M.X., Tran C.T.: Design Guide for Concrete Filled Tubular Members with High Strength Materials - An extension of Eurocode 4 Method to C90/105 Concrete and S550 Steel, Building and Construction Authority of Singapore, Singapore, 2015.

[16] Xiong, M.X.: Fire Resistance of Ultra-High Strength Concrete Filled Steel Tubular Columns, PhD Dissertation, National University of Singapore, Singapore, 2013.

[17] ISO-834-1: Fire-Resistance Tests-Elements of Building Construction Part1: General Requirements, International Standard ISO-834, Geneva, 1999.

[18] Kodur, V.K.R., Yu, B.L., Dwaikat, M. M. S.: A simplified approach for predicting temperature in reinforced concrete members exposed to standard fire, Fire Safety Journal, 10 (2013), 2, 253-271.

[19] Dai, X.H., Lam, D.: Shape effect on the behaviour of axially loaded concrete filled steel tubular stub columns at elevated temperature, J. Constr. Steel Res., 73 (2012), 117-127.

[20] Xiong, M.X. and Liew, J.Y.R.: Spalling behavior and residual resistance of fibre reinforced ultra-high performance concrete after elevated temperatures, Materiales de Construcción, 65 (2015), 320, 1-10.

[21] Yin, J., Zha, X.X., Li, L.Y.: Fire resistance of axially loaded concrete filled steel tube columns, Journal of constructional steel research, 62 (2006), 723-729.

[22] ECS, Eurocode 2: Design of Concrete Structures-Part 1-2, General Rules-Structural Fire Design, EN 1992-1-2, European Committee for Standardization, 2004.

[23] ECS, Eurocode 3: Design of Steel StructuresPart 1-2, General Rules-Structural Fire Design, EN 1993-1-2, European Committee for Standardization, 2005.

[24] ECS, Eurocode 4: Design of Composite Steel and Concrete Structures-Part 1-2, General Rules-Structural Fire Design, EN 1994-1-2, European Committee for Standardization, 2005.

[25] Chen, Y.S., Wu, B., Pan, T.L.: A novel constitutive model for beam-column element, Engineering Review, 36 (2016), 1, 41-52.

[26] Pešić, I, Lanc, D, Turkalj, G.: Non-linear thermal buckling analysis of thin-walled beam structures, Engineering Review, 35 (2015), 3, 239-245.

[27] Ellobody, E., Young, B., Lam, D.: Behaviour of normal and high strength concrete filled compact steel tube circular stub column, J. Constr. Steel Res., 66 (2006), 1030-1046. 